\title{
ERGONOMICS AND FUNCTIONAL REQUIREMENT IN THE DESIGN OF STUDENTS' FURNITURE IN MOSHOOD ABIOLA POLYTECHNIC ABEOKUTA NIGERIA
}

\author{
ADEKUNLE IBRAHIM MUSA-OLOKUTA*1 \\ ${ }^{1}$ Department of Mechanical Engineering, Olabisi Onabanjo University, Ago Iwoye, Ibogun \\ Campus, Ogun State, Nigeria
}

\begin{abstract}
A total of five hundred and fifty students were randomly selected in three schools of engineering; communication; science and technology. The existing furniture dimensions were measured. The maximum and minimum table height was determined. The results showed seat heights as compared with the students body sizes are expected to be in the range of $33.85 \mathrm{~cm}$ and $36.54 \mathrm{~cm}$. Table height is expected to be in the range of $61.08 \mathrm{~cm}$ and 64.48 $\mathrm{cm}$. The study concluded that data on the anthropometric dimension of students are provided and this could be used as database for the planning of future furniture in the lecture rooms.
\end{abstract}

Keywords: Anthropometric, Students, furniture, measurement, lecture room, mismatch

\section{INTRODUCTION}

Ergonomics is that the study of man or woman at work. More precisely, it is the study of people using equipment in specific environments to perform certain tasks [1]. During the past decade, research in ergonomic had led to heightened interest within the technology of labor and furniture design supported biomechanics of the human body. These researches focused on the event of latest principle for the design of chairs and desks within the workplace [2]. Bridger [3] and Chou and Hsiao [4] believed that anthropometry could also be a search area in ergonomics that affect the measurement of human body dimensions and certain physical characteristics. Inconsistent design of institution furniture is one of the good contributing factors to back pain among the scholars as indicated in some researchers [5].

Back pains even have a substantial economic impact [6]. By understanding human anatomy, kinetics and principles of physics, the ergonomist can develop best practices to weaken injury and maximize efficiency within the workplace, home and faculty. Much study has been done on the matter of seating, because of the increased use of computers within the workplace. Within us alone, 40 million people sit in office chairs every workday. The goal of office chair designers is to make chairs that fit the foremost important range of sizes possible. Most workers don't have a choice of chair size or style once they're hired. Manufacturers have tried to make chairs that are adjustable in several critical dimensions. Even so, chair manufacturer Herman Miller estimates that chairs that are designed to suit $95 \%$ of the population probably only accommodate $75 \%$. The quantity may even be lower thanks to the shortage of the users to properly adjust the chair to suit them.

They contest that the "one size fits all" solution is that the simplest and developed how to facilitate the successful accommodation of a greater percentage of the population. Instead of working with a "middle-out approach" resulting in one chair design, they designed the same chair in three sizes, using an "end-to-middle" approach. They

\footnotetext{
* Corresponding author email: musa.adekunle@ mapoly.edu.ng

(C) 2021 Alma Mater Publishing House
} 
compare this to the range of sizes that shoes or bicycles are available. They contend that nearly everyone will fit one among the three chairs, even with minimal adjustment. This method resulted within the Aeron chair [7].

Postures differ counting on the task at hand - people tend to lean forward while reading at a desk, lean backward while talking on the phone and have their upper extremities in any kind of positions [8]. The principles that follow are for a user sitting in what's called the 90-90-90 position. These resulted to the lower legs to be at angle $90^{\circ}$ to the horizontal ground. Similarly, knees are also bent at angle $90^{\circ}$, with respect to the hip. Their upper legs are parallel to rock bottom and their back is in tuned with the rear rest [9]. There are four major dimensions to account for when designing a chair, the seat height, seat depth, seat width and back height.

The reported industry average seat height is $43.18 \mathrm{~cm}$ while the house chairs in adjustable task is 40.6 to $50.8 \mathrm{~cm}$ [10]. Determining seat depth requires some calculation. The anthropometric measure used most often is that the buttock- popliteal length. Seat depth recommendations range from 33.00 to $43.00 \mathrm{~cm}$ [10]. The user should be able to sit with their back against the rear rest and still have space between the sting of the seat and thus the back of the knee [11]. A minimum of 5.80 to $7.62 \mathrm{~cm}$ and a maximum of 15.24 to $20.32 \mathrm{~cm}$ are recommended [10].

The requirements for seat width are somewhat more flexible than those for seat height and depth. In most cases, the minimum width is all that's required. Usually, there is a two-way constraint on a dimension - too high is just as bad as too low [1]. Unless a seat is extremely contoured, excess width doesn't generally affect the user. The minimum width is that the hip breadth plus an allowance for movement [10]. Of all the dimensions, the rear rest height is most enthusiastic to the type of activity the sitter is engaged in. Back rest heights are classified as low level - below the shoulder blades, mid-level- upper back and shoulder, and high level - head and neck [1], for task chairs, the upper and lower back should be supported. A space between the seat and thus the backrest to allow room for the buttocks is additionally recommended. The angle of the rear rest to the seat ranges from between 90 to $110^{\circ}[9]$.

Typically, the backs should not be above the lowest of the shoulder blades [11]. However, it's harder to develop criteria for the rear height of an occasional chair. Therefore, this study is an attempt to use local anthropometric data to develop the suitable table and chair for our tertiary institutions. This might definitely fill the gap of using foreign anthropometric data instead of the local suitable data yet untapped in Nigeria.

The purpose of this study is to obtain the anthropometric data of students of Moshood Abiola Polytechnic, Abeokuta. The data obtained by this study are getting to be used to determine the optimal measurements of the classroom tables and chairs.

\section{MATERIALS AND METHODS}

A total of 550 students participated in the study with 350 male and 200 female randomly selected from different department in three schools of engineering, communication and science and technology of Moshood Abiola Polytechnic Abeokuta Ogun State Nigeria.

The body size of each student was assessed using standard anthropometric measurement techniques based on a study by [2]. All anthropometric measurements were taken while the students sit erect on a flat horizontal surface with knees bent at $90^{\circ}$ and feet (without shoe) flat on an adjustable horizontal surface. Height (stature) was taken while the students were standing erect without shoe.

Figure 1 shows clearly the exact location of the entire anthropometric dimension. This is important in ensuring that the measurement processes for all participants are done correctly and accurately to minimize the measurement error in data collection. All measurements were measured in centimeter $(\mathrm{cm})$ with the exception of the body mass that was in kilogram $(\mathrm{Kg})$.

The following variable represents relevant dimensions of classroom furniture (chair/table) and therefore the body measurement.

\subsection{Measured characteristics of existing furniture}

- Seat depth: The chair seat depth is that the horizontal distance of the sitting surface from the back of the seat, at a point where it is assumed that the buttock begins to the front of the seat. 
- Seat slope: The chair seat slope is that the direction and angle of pitch of the seat of the chair.

- Table height: The table height is that the vertical distance from the ground to the highest of the front edge of the desk or table.

- Table clearance: The table clearance is that the vertical distance from the floor to the bottom of the front edge of the desk or table.

- Table slope: The table slope is that the angle of pitch of the top of the desk.
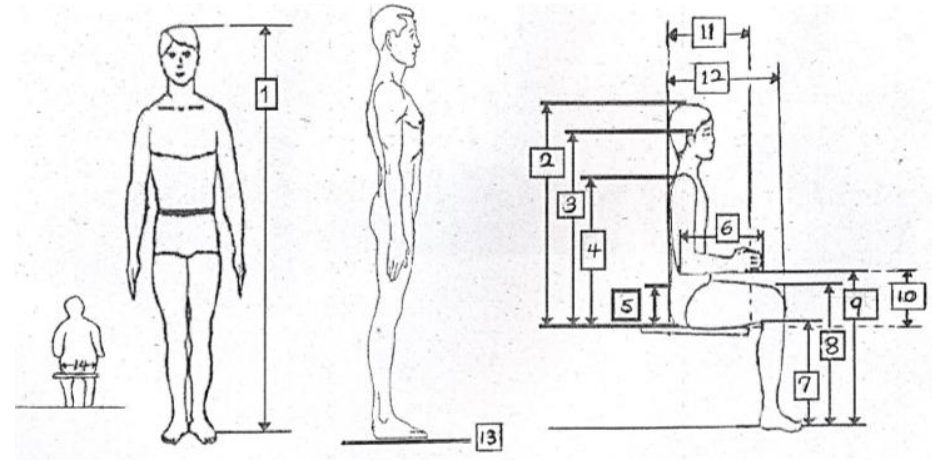

Fig. 1. Measured anthropometric data:

1 - body height; 2 - sitting height; 3 - sitting eye height; 4 - sitting shoulder height; 5 - thigh clearance;

6 - forearm hand length; 7 - popliteal height; 8 - sitting knee height; 9 - sitting elbow height; 10 - sitting elbow rest height; 11 - buttock-popliteal length; 12 - buttock knee length; 13 - body weight; 14 - hip breadth.

\subsection{Measuring devices}

The equipment's used for this study were the following: (i) weighing machine - floor type (standio-meter), modelhealth scale ZT-160, micro field, England; (ii) venier caliper - range 0-68 cm with error 0.1 mm for the measuring human body; (iii) metal tape and angle finder- This was used to measure the chair and table dimensions and with angle finder for seat and table slopes.

\subsection{Data analysis}

The data was analyzed statistically by using SPSS 21.0 statistical package and Microsoft Excel (2007) programs. Descriptive and analytical statistics was generated. The anthropometrical data was analyzed using average, minimum, maximum, standard deviation, $5 \%$-ile, $50 \%$-ile and $95 \%$-ile according to gender, age and school.

\subsection{Mismatch between school furniture and anthropometric dimension}

The comparison between student body size and furniture dimension was done by using the criteria of mismatch as reported by Parcells et al (1999) as follows:

1. Popliteal height and seat height mismatch: seat height $=>95 \%$ or $<88 \%$ of popliteal height.

2. Buttock-popliteal length and seat depth: $\underline{\text { seat depth }}=<80 \%$ or $>95 \%$ buttock-popliteal length.

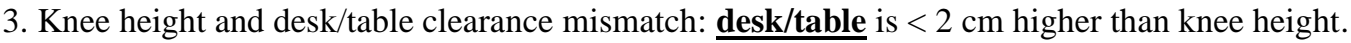

4. Elbow rest height and table height mismatch.

Determination of acceptable elbow height with shoulder flexion and abduction (hE), the measurements of shoulder height $(\mathrm{hS})$, vertical elbow rest height (hEv), upper arm length $(\mathrm{U}=\mathrm{hS}-\mathrm{hEv})$, shoulder flexion (U), and shoulder abduction was used in the following equation:

$$
h E=h E v+U[(1-\cos \theta)+\cos \theta(1-\cos \beta)]
$$

Maximum desk height was determined by: $\mathrm{hE}=0.8517 \mathrm{hEv}+0.1483 \mathrm{hS}$ and this were used for the design.

\section{RESULTS AND DISCUSSION}

\subsection{Furniture characteristics in the Schools}

Table 1 shows the different dimension of tables and chairs used in the three selected schools. The furniture's that are currently in use in Moshood Abiola Polytechnic are of different designs and dimensions which shows that the furniture's are supplied by different manufacturer (Figure $2 \div$ Figure 5 ). 


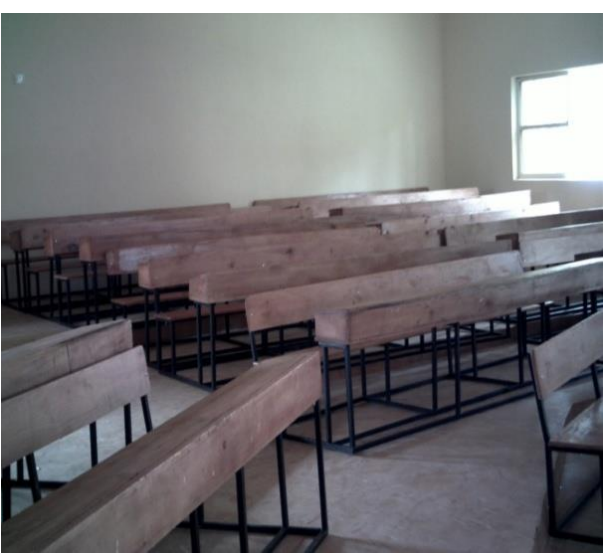

Fig. 2. Existing furniture in one of the classrooms.

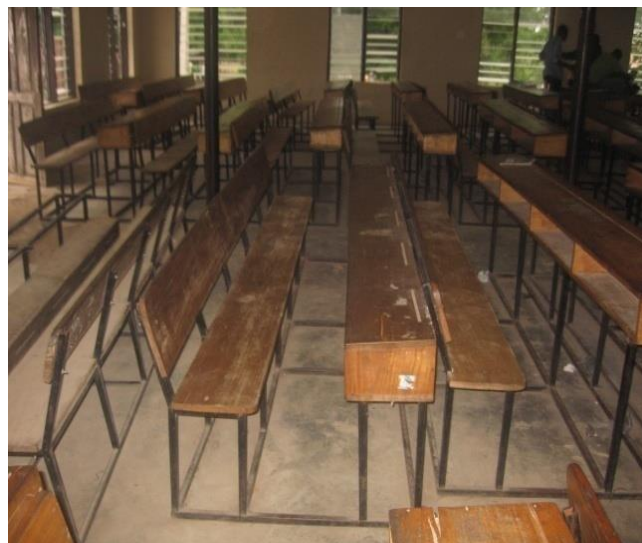

Fig. 4. Existing furniture in one of the classroom.

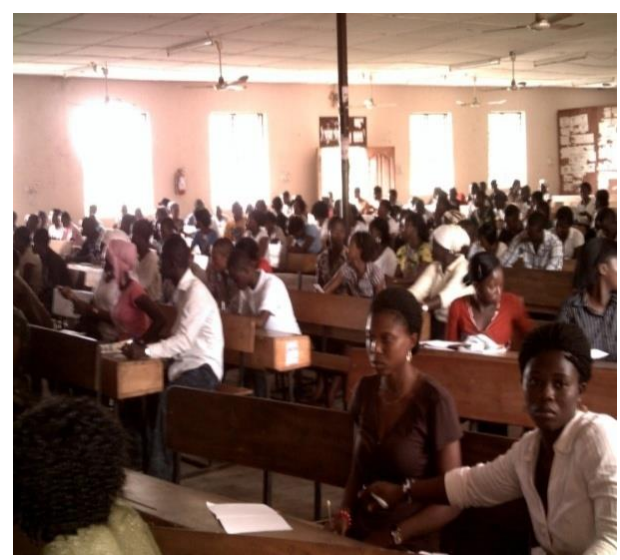

Fig. 3. Student on the existing furniture's.

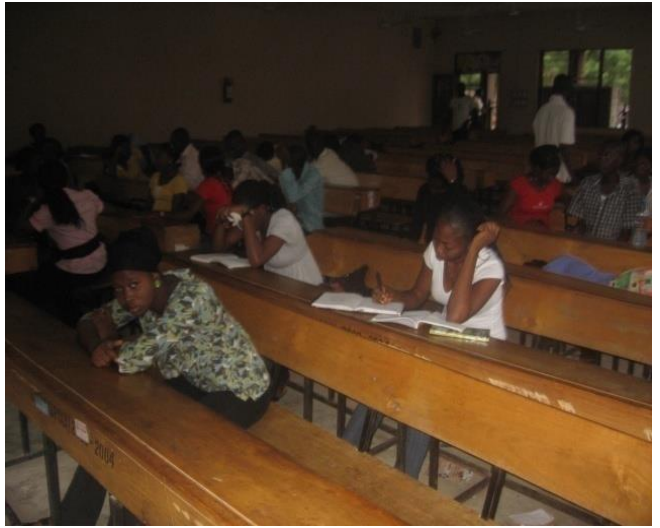

Fig. 5. Student on the existing furniture.

Table 1. Furniture characteristics of the existing furniture.

\begin{tabular}{|c|c|c|c|c|c|c|c|}
\hline School & $\begin{array}{c}\text { Seat height } \\
(\mathrm{cm})\end{array}$ & $\begin{array}{c}\text { Seat depth } \\
(\mathrm{cm})\end{array}$ & $\begin{array}{c}\text { Seat slope } \\
\text { Angle }(\mathrm{deg})\end{array}$ & $\begin{array}{c}\text { Table } \\
\text { depth }(\mathrm{cm})\end{array}$ & $\begin{array}{c}\text { Table } \\
\text { height } \\
(\mathrm{cm})\end{array}$ & $\begin{array}{c}\text { Clearance } \\
(\mathrm{cm})\end{array}$ & $\begin{array}{c}\text { Surface } \\
\text { slope angle } \\
(\mathrm{deg})\end{array}$ \\
\hline Engineering & 44.00 & 35.00 & $3^{\circ}$ & 29.00 & 75.50 & 60.00 & $10^{\circ}$ \\
\hline Communication & 41.00 & 29.00 & $3^{\circ}$ & 29.00 & 69.00 & 55.00 & $10^{\circ}$ \\
\hline Science & 45.00 & 33.00 & $3^{\circ}$ & 28.00 & 75.00 & 01.00 & $10^{\circ}$ \\
\hline
\end{tabular}

Though the chair slope and surface slope angles were the same for the furniture in these institutions, the fact that exist differences in other, but the dimensions suggest that the tables and chairs were constructed by different company.

\subsection{Anthropometric dimensions of the Students}

The anthropometric data of the students are presented in Tables 2 to 4 in the form of means, standard deviations (SD) and $5^{\text {th }}, 50^{\text {th }}$ and $95^{\text {th }}$ percentiles. Also included are the minimum, maximum of the dimensions and the body mass. Table 2 to Table 4 actually showed the summary of anthropometric dimension for students in different schools respectively.

Table 2. Summary of anthropometric dimensions among male students.

\begin{tabular}{|l|c|c|c|c|c|c|c|}
\hline \multirow{2}{*}{ Anthropometric dimension } & \multicolumn{7}{|c|}{ MALE (n=350) } \\
\cline { 2 - 8 } & Mean & SD & Min & Max & $\mathbf{5 \% \text { ile }}$ & $\mathbf{5 0} \%$ ile & 95 \%ile \\
\hline Age (Yrs.) & 23.9 & 1.7 & 20.0 & 27.0 & 20.0 & 24.0 & 27.0 \\
\hline Sitting height (cm) & 83.8 & 3.2 & 78.0 & 89.0 & 78.0 & 84.0 & 89.0 \\
\hline Sitting elbow rest height (cm) & 19.99 & 1.3 & 18.5 & 22.0 & 18.5 & 19.6 & 22.0 \\
\hline Sitting elbow height (cm) & 59.7 & 2.8 & 55.0 & 65.0 & 56.0 & 59.5 & 65.0 \\
\hline
\end{tabular}




\begin{tabular}{|l|c|c|c|c|c|c|c|}
\hline Sitting shoulder height $(\mathrm{cm})$ & 54.1 & 2.4 & 50.0 & 59.0 & 50.0 & 54.0 & 59.0 \\
\hline Thigh clearance $(\mathrm{cm})$ & 14.9 & 1.2 & 13.0 & 18.0 & 13.0 & 15.0 & 17.0 \\
\hline Knee height $(\mathrm{cm})$ & 53.1 & 3.0 & 48.0 & 59.0 & 48.0 & 53.0 & 59.0 \\
\hline Popliteal height $(\mathrm{cm})$ & 39.7 & 1.8 & 36.0 & 42.0 & 36.0 & 40.0 & 42.0 \\
\hline Standing height $(\mathrm{cm})$ & 169.5 & 6.0 & 161.0 & 180.5 & 162.0 & 169.5 & 180.5 \\
\hline Body mass $(\mathrm{kg})$ & 58.4 & 3.4 & 51.0 & 65.5 & 52.5 & 58.0 & 65.5 \\
\hline Buttock popliteal length $(\mathrm{cm})$ & 38.7 & 2.1 & 35.0 & 42.0 & 35.0 & 39.0 & 42.0 \\
\hline Hip breadth $(\mathrm{cm})$ & 32.8 & 1.4 & 30.0 & 36.0 & 31.0 & 33.0 & 35.0 \\
\hline Eye height $(\mathrm{cm})$ & 74.3 & 3.7 & 68.0 & 87.0 & 70.0 & 73.0 & 79.0 \\
\hline Buttock knee length $(\mathrm{cm})$ & 58.3 & 2.2 & 52.0 & 61.0 & 55.0 & 58.0 & 61.0 \\
\hline Forearm hand length $(\mathrm{cm})$ & 46.5 & 2.4 & 42.0 & 50.0 & 42.0 & 47.0 & 50.0 \\
\hline
\end{tabular}

(All measurements in $\mathrm{cm}$ except body mass in $\mathrm{kg}$ )

Table 3. Summary of anthropometric dimensions among female students.

\begin{tabular}{|l|c|c|c|c|c|c|c|}
\hline \multirow{2}{*}{ Anthropometric dimension } & \multicolumn{7}{|c|}{ FEMALE (n=200) } \\
\cline { 2 - 8 } & Mean & SD & Min & Max & $\mathbf{5 \% \text { ile }}$ & $\mathbf{5 0} \%$ ile & 95 \%ile \\
\hline Age (Yrs.) & 22.0 & 1.9 & 19.0 & 26.0 & 19.0 & 22.0 & 26.0 \\
\hline Sitting height (cm) & 74.7 & 2.6 & 69.0 & 78.0 & 70.0 & 75.0 & 78.0 \\
\hline Sitting elbow rest height (cm) & 17.7 & 1.2 & 15.0 & 19.0 & 15.0 & 17.0 & 19.0 \\
\hline Sitting elbow height (cm) & 56.6 & 3.3 & 52.0 & 70.0 & 52.0 & 56.0 & 61.0 \\
\hline Sitting shoulder height (cm) & 48.3 & 1.5 & 47.0 & 52.0 & 47.0 & 50.0 & 51.0 \\
\hline Thigh clearance (cm) & 13.2 & 1.0 & 12.0 & 15.0 & 12.0 & 13.0 & 15.0 \\
\hline Knee height (cm) & 46.7 & 2.1 & 42.0 & 51.0 & 43.0 & 47.0 & 49.0 \\
\hline Popliteal height (cm) & 36.4 & 5.6 & 28.0 & 40.0 & 33.0 & 33.0 & 39.0 \\
\hline Standing height (cm) & 158.7 & 3.3 & 150.0 & 161.5 & 150.0 & 157.0 & 161.5 \\
\hline Body mass (kg) & 56.9 & 3.2 & 51.5 & 62.5 & 51.5 & 56.8 & 62.0 \\
\hline Buttock popliteal length (cm) & 43.8 & 1.2 & 42.0 & 46.0 & 42.0 & 44.0 & 46.0 \\
\hline Hip breadth (cm) & 32.3 & 2.0 & 27.0 & 35.0 & 28.0 & 33.0 & 35.0 \\
\hline Eye height (cm) & 65.3 & 2.3 & 58.0 & 69.0 & 63.0 & 65.0 & 69.0 \\
\hline Buttock knee length(cm) & 54.9 & 1.5 & 52.0 & 57.0 & 52.0 & 55.0 & 57.0 \\
\hline Forearm hand length (cm) & 44.3 & 2.0 & 39.0 & 47.0 & 40.0 & 45.0 & 47.0 \\
\hline
\end{tabular}

(All measurements in cm except body mass in $\mathrm{kg}$ ).

Table 4. Summary of anthropometric dimensions among students.

\begin{tabular}{|l|c|c|c|c|c|c|c|}
\hline Anthropometric Dimension & Mean & SD & Min & Max & $\mathbf{5 \%}$ ile & 50\%ile & 95\%ile \\
\hline Age (Yrs.) & 23.0 & 2.1 & 19.0 & 27.0 & 20.0 & 23.0 & 27.0 \\
\hline Sitting height (cm) & 80.5 & 5.0 & 69.0 & 89.0 & 72.0 & 80.0 & 89.0 \\
\hline Sitting elbow rest height (cm) & 18.96 & 1.87 & 15.0 & 22.0 & 16.0 & 19.0 & 22.0 \\
\hline Sitting elbow height (cm) & 58.5 & 3.4 & 52.0 & 70.0 & 55.0 & 58.0 & 65.0 \\
\hline Sitting shoulder height (cm) & 52.0 & 3.0 & 8.0 & 59.0 & 47.0 & 52.0 & 59.0 \\
\hline Thigh clearance (cm) & 14.3 & 1.4 & 12.0 & 18.0 & 12.0 & 14.0 & 17.0 \\
\hline Knee height (cm) & 50.8 & 4.1 & 42.0 & 59.0 & 44.0 & 51.0 & 58.0 \\
\hline Popliteal height (cm) & 38.5 & 4.4 & 28.0 & 42.0 & 36.0 & 39.0 & 42.0 \\
\hline Standing height (cm) & 164.8 & 8.0 & 150.0 & 180.5 & 153.0 & 163.5 & 179.5 \\
\hline Body mass (kg) & 57.9 & 3.5 & 51.0 & 65.5 & 52.1 & 58.0 & 65.0 \\
\hline Buttock popliteal length (cm) & 40.5 & 3.1 & 35.0 & 46.0 & 35.0 & 40.0 & 45.0 \\
\hline Hip breadth (cm) & 32.6 & 1.6 & 27.0 & 36.0 & 29.0 & 33.0 & 35.0 \\
\hline Eye height (cm) & 71.0 & 5.4 & 58.0 & 87.0 & 63.0 & 71.0 & 79.0 \\
\hline Buttock knee length(cm) & 57.0 & 2.5 & 52.0 & 61.0 & 52.0 & 57.0 & 61.0 \\
\hline Forearm hand length (cm) & 45.7 & 2.5 & 39.0 & 50.0 & 42.0 & 45.0 & 50.0 \\
\hline
\end{tabular}

(All measurements in $\mathrm{cm}$ except body mass in $\mathrm{kg})(\mathrm{n}=550)$ 


\subsection{Mismatch between students body dimension and the classroom furniture's}

Mismatch was identified as when the seat height is either $>95 \%$ or $<88 \%$ of the popliteal height $(\mathrm{Ph})$. This will probably allow for clearance of between 55 and $12 \%$ of $\mathrm{Ph}$ [2]. The seat height (Sh) in the three selected schools should be $36.54 \mathrm{~cm}$ and $33.85 \mathrm{~cm}$ as against $43.33 \mathrm{~cm}$ of the existing seat. The result of the mismatch was authenticated with the similar study $[14,15]$.

In line with aforementioned above, the seats in the school of Engineering were supplied by different furniture maker without course to the standard anthropometric dimension of the students. The Sh in the School of Engineering is $44.00 \mathrm{~cm}$, Communication $41.00 \mathrm{~cm}$ and Sciences $45.00 \mathrm{~cm}$ respectively. It could be deduced that few of the students in the school may found the seat convenient and comfortable because it was produced with proxy dimension which adequately fit their body dimension of $\mathrm{Ph}$.

\subsection{Mismatch between sitting elbow rest and table height}

The functional elbow height is determined by equation (1) [2]:

$$
\mathrm{hE}=\mathrm{hEv}+\mathrm{U}[(1-\cos \theta)+\cos \theta(1-\cos \beta)]
$$

where: $\mathrm{hE}$ is vertical distance from the top of the table to the standard sitting surface; $\mathrm{hEv}$ - Elbow rest height.

$$
\mathrm{U}=\mathrm{hS}-\mathrm{hEv}
$$

where: hS is sitting shoulder height; $\theta$ - Shoulder flexion angle; $\beta$ - Shoulder abduction angle.

Reference to Chaffin and Anderson [13], the maximum and minimum acceptable angle of the shoulder during writing is $0-25^{\circ}$ of the shoulder flexion and $0-20^{\circ}$ shoulder abduction.

For flexion angle, the corresponding cosine are $1.00\left(0^{\circ}\right)$ and $0.9063\left(25^{\circ}\right)$ and for the abduction angles, the corresponding cosine are $1.00\left(0^{\circ}\right)$ and $0.9397\left(20^{\circ}\right)$.

From equation (1), therefore:

$$
\begin{gathered}
\mathrm{hE}=\mathrm{hEv} \\
\text { Maximum table height }(\mathrm{Mth})=\mathrm{Sh}+\mathrm{hE}
\end{gathered}
$$

The maximum functional elbow height is determined by the vertical elbow height alone $(\mathrm{hEv})$.

Hence, from equation (4) above:

$$
\mathrm{Mth}=\mathrm{hE}=\mathrm{hEv}+\mathrm{U}[(1-\cos \theta)+\cos \theta(1-\cos \beta)]
$$

substitute the values,

$$
h E=h E v+U[(1.00-0.9063)+0.9063(1.00-0.9397)]
$$

From equation (2), therefore, $\mathrm{hE}$ is Maximum function elbow height; $\mathrm{hEv}$ - vertical elbow rest height; $\mathrm{hS}$ Shoulder height.

For each student, the functional elbow height was added to each of the seat height (Sh) to give the respective table height equation (4).

The maximum table heights (Mth) were then compared with the existing table height (Table 1). Thus, the elbowshoulder and the table height were defined to be mismatched when the table was either shorter than the minimum table height or taller than the maximum table height. 
From equation (3):

$$
\mathrm{hEv}=18.196 \pm 1.87 \mathrm{~cm}
$$

The seat height:

$$
\mathrm{Sh}=50 \% \text { ile of } \mathrm{Ph}+0.25 \mathrm{~cm}
$$

allowance

$=39.00 \mathrm{~cm}+0.25=39.25 \mathrm{~cm}$

The Minimum table height $=\mathrm{Sh}+$ Minimum functional elbow rest height $=40.25 \mathrm{~cm}+(18.96 \pm 1.87) \mathrm{cm}=61.08$ $\mathrm{cm}$ and $57.3 \mathrm{~cm}$.

Maximum functional elbow height:

$$
\begin{gathered}
\mathrm{hE}_{\max }=0.851 \mathrm{hEv}+0.143 \mathrm{hS}=[0.851 \times(18.96 \pm 1.87)] \mathrm{cm}+(0.143 \times 52.47) \mathrm{cm} \\
=(17.73+7.503) \mathrm{cm} \text { or }(17.09+7.50) \mathrm{cm}, \\
\mathrm{hE}_{\max }=25.23 \mathrm{~cm} \text { or } 24.59 \mathrm{~cm}
\end{gathered}
$$

therefore,

$$
\begin{aligned}
& \text { Maximum table height }\left(\mathrm{Th}_{\max }\right)=\mathrm{Sh}+\mathrm{hE}_{\max }=(39.25+25.23) \mathrm{cm} \\
& \text { or }(39.25+24.59) \mathrm{cm} \\
& =64.48 \mathrm{~cm} \text { or } 63.84 \mathrm{~cm}
\end{aligned}
$$

The study showed that the three selected school has $73.17 \mathrm{~cm}$ (average) for the existing table height while the designed and calculated minimum and maximum table height has $61.08 \mathrm{~cm}$ and $64.48 \mathrm{~cm}$ respectively. The results revealed that the existing table could not be comfortable for the students due to the facts that it is too high for the learning. The result also showed that there is mismatched between sitting elbow rest height, shoulder height and table height for the students.

\subsection{Design parameters for the student's function}

Seat design: for the functional seat design for student, several parameters such as seat height, seat depth and seat width needed to be considered.

Seat height Sh is the $5 \%$ ile of the:

$$
\mathrm{Ph}=36.0 \mathrm{~cm}+0.45 \mathrm{~cm}(45 \% \text { allowance })=36.45 \mathrm{~cm}
$$

Seat depth is also the $5 \%$ ile of the Buttock popliteal length $=35.0 \mathrm{~cm}$.

Seat width is the $95 \%$ ile of Hip breadth:

$$
\mathrm{hB}=35.0 \mathrm{~cm}+0.15 \mathrm{~cm}(15 \% \text { allowance })=35.15 \mathrm{~cm}
$$

Table design: the design of table for the selected schools can be determined with 5\%ile of sitting elbow rest height and the shoulder height.

From equation (8) above:

The functional elbow rest height $=0.851 \mathrm{hEv}+0.1483 \mathrm{hS}=(0.851 \times 16.00) \mathrm{cm}+(0.1483 \times 47.0) \mathrm{cm}=20.59$ $\mathrm{cm}$

The maximum table height $=\mathrm{hS}+$ functional elbow rest height + shoe heel allowance. 
From above, Seat height $\mathrm{Sh}=36.45 \mathrm{~cm}$, show heel allowance $=0.45(45 \%)$.

Maximum table height $=(36.45+20.59+0.45) \mathrm{cm}=57.49 \mathrm{~cm}$.

The table width $=95 \%$ ile hip breadth $+15 \%$ allowance for clothing $+15 \%$ allowance as clearance $=(35.0+0.15$ $+0.15) \mathrm{cm}=53.30 \mathrm{~cm}$.

The table depth $=50 \%$ ile of the forearm hand length $=47.00 \mathrm{~cm}$.

The data of the anthropometric dimension of the study were based on the student's anthropometric dimension measurement of three selected schools (Engineering. Communication, Sciences). The mean age of the respondents is $23 \pm 2.07 \mathrm{~cm}$ years and the mean stature of the male students is $169.49 \mathrm{~cm}$ as against $158.71 \mathrm{~cm}$ female respectively. The study showed that body mass of the respondents are $58.42 \mathrm{~kg}$ and $56.94 \mathrm{~kg}$ for male and female respectively (Table 2 and Table 3). The result also showed that Buttock popliteal length for female students is $43.78 \mathrm{~cm}$ as against $38.66 \mathrm{~cm}$ for male students. This revealed that, female students have a big buttock compared to male. Table 2 and Table 3 further showed that the sitting heights are $83.82 \mathrm{~cm}$ and $74.72 \mathrm{~cm}$ for male and female respectively.

The design parameters of the furniture were compared with similar studies [2, 14]. Musa [14] study designed a tables and chairs for tertiary institutions in Ogun State. The present results showed that the seat height for Moshood Abiola Polytechnic students is $36.45 \mathrm{~cm}$ while Musa [14] reported $41.40 \mathrm{~cm}$. The table height of $57.49 \mathrm{~cm}$ was compared with $56.33 \mathrm{~cm}$ [14]. This showed that the present study table is $1.16 \mathrm{~cm}$ higher.

The data collected on the mismatch between the students' anthropometric dimensions and the existing furniture available. The three selected schools indicated and urgent and immediate solution in Nigeria as most of the students could not find the existing furniture suitable. Interaction showed that most of the students find it difficult to sit comfortably due to furniture too high, too low or too shallow. The study revealed that students anthropometric dimension is dependent on age and gender and the anthropometric data showed variability among the students in all the selected schools.

\section{CONCLUSION}

The study described the constraint in the used of the foreign furniture in Moshood Abiola Polytechnic Abeokuta. It had been evident that the furniture supplied for students used were designed without consideration for the anthropometric measurements of the top users. Most of the students are using furniture that are too low, too high, too deep or too shallow. The author believed that majority of the furniture supplied in our tertiary institutions were designed consistent with the measurements of students from other countries which differ greatly from the one employed by Nigerian students.

The author has succeeded in providing additional data on the anthropometric dimension of Moshood Abiola polytechnic Abeokuta students. This data might be very useful in guideline of designing future furniture used in the lecture rooms and lecture theater and conference hall. Furthermore, the author recommended that this anthropometric measurement could even be used to produce prototype furniture for the students. The information could even be used as database for the planning of furniture for Nigerian tertiary institution students since most of the students an equivalent characteristic.

\section{REFERENCES}

[1] Pheasant, S., Body space: Anthropometry, ergonomics and the design of work, Second edition, Taylor and Francis, London, 1998.

[2] Parcells, C., Stommel, M., Hubbard, R.P., Mismatch of classroom furniture and students body dimensions: Empirical findings and health implications, Journal of Adolescent Health, vol. 24, 1999, p. 265-273.

[3] Chou, J.R., Hsiao, S.W., An anthropometric measurement for developing an electric Scooter, International Journal of Industrial Ergonomics, vol. 35, 2005, p. 1047-1063.

[4] Bridger, R.S., Introduction to ergonomics, McGraw-Hill Incorporated, St. Louis, 1995.

[5] Aagaard-Hansen, J., Storr-Paulsen, A., A comparative study of three different kind of school furniture, Ergonomics, no. 38, 1995, p. 1025-1035. 
[6] Nemi, S.M., Levoska, S., Rekola K.E., Neck and shoulder symptoms of high school students and associated, Psychosocial factors, Journal of Adolescent Health, vol. 20, 1997, p. 238-242.

[7] Stumpf, B., Chadwick, D., Dowell, B., The anthropometrics of fit: Ergonomic criteria for the design of the Aeron chair, 2002, Retrieved December 11, 2004 from http://www.hermanmiller.com/hm/content/research_summaries/wp_Anthropometrics.pdf_(15.03.2021).

[8] Stumpf, B., Chadwick, D., Dowell, B., The kinematics of sitting. Retrieved December 11, 2004 from http://www.hermanmiller.com/hm/content/research_summaries/wp_Kinematics_of_Sitting.pdf (15.03.2021).

[9] BIFMA, BIFMA ergonomics guideline ultimate test for fit, 2005. Retrieved February 28, (BIFMA Business and Institutional Furniture Manufacturer's Association).

[10] Cranz, G., The chair: Rethinking culture, body, and design (1st ed.), New York, W.W. Norton, 1998.

[11] Goonetilleke, R., Song, F., An experimental study on seat depth, ASEAN Ergonomics, 1997.

[12] Thariq, M.G.M, Munasinghe, H.P., Abeysekara J.D., Designing chairs with mounted desktop for university students; Ergonomics and comfort, International Journal of Industrial Ergonomics, vol. 40, 2010, p. 8-18.

[13] Chaffin, D., Anderson, G., Occupational Biomechanics, Wiley, 1991.

[14] Musa, A.I., Ergo-analysis and design of tables and chairs for use in tertiary institution in Abeokuta, Nigeria. A dissertation submitted for the award of Master of Engineering (M. Eng) in Mechanical Engineering Department, Federal University of Agriculture, Abeokuta, Nigeria, 2011.

[15] Ismaila, S.O., Musa, A.I., Adejuyigbe, S.B., Akinyemi, O.D., Anthropometric design of furniture for use in tertiary institutions in Abeokuta, South-Western Nigeria, Engineering Review, vol. 33, no. 3, 2013, p. 179-192. 